Systematic Review

\title{
Unilateral Versus Bilateral Balloon Kyphoplasty for Osteoporotic Vertebral Compression Fractures: A Systematic Review of Overlapping Meta-analyses
}

\author{
Cui Zhiyong, MD1, Tian Yun, MD1', Feng Hui, MD1, Yang Zhongwei, MD', and \\ Liu Zhaorui, MD²
}

From: ${ }^{1}$ Department of Orthopedic Trauma, Peking University Third Hospital, Beijing, China; ${ }^{2}$ Peking University

Sixth Hospital, Beijing, China

Address Correspondence: Tian Yun, MD

Department of Orthopedics, Peking University Third Hospital

No 49 Huayuan Road

Beijing, China

E-mail: tiany@bjmu.edu.cn

Disclaimer: This review was

supported by the Beijing

Municipal Commission of

Science and Technology (Grant No.A71479-05).

Conflict of interest: Each author

certifies that he or she, or a member of his or her immediate

family, has no commercial association (i.e., consultancies, stock ownership, equity interest, patent/licensing arrangements, etc.) that might pose a conflict of

interest in connection with the submitted manuscript.

Manuscript received: 11-02-2017 Revised manuscript received: o6-14-2018

Accepted for publication: 06-22-2018

Free full manuscript: www.painphysicianjournal.com
Background: There have been many meta-analyses and systematic reviews that have discussed the differences between unilateral and bilateral balloon kyphoplasty. However, their conclusions regarding the efficacy and safety of bilateral balloon kyphoplasty in the treatment of osteoporotic vertebral compression fractures (OVCFs) are discordant.

Objective: We attempted to select the best evidence review to determine the differences between unilateral and bilateral balloon kyphoplasty, and we wanted to determine the best treatment approach for OVCFs.

Study Design: A systematic review of overlapping meta-analyses

Setting: The electronic databases of PubMed, Embase and The Cochrane Library were searched The search extended through Sept. 30, 2017. Moreover, we manually searched the last 10 years of conference reports and papers from the Peking University Health Science Library and consulted 2 experts in the field for any additional relevant information.

Methods: We followed the Preferred Reporting Items for Systematic Reviews and Meta-Analysis (PRISMA) Statement and used "A Measurement Tool to Assess Systematic Reviews" (AMTASR) and the Oxford Levels of Evidence to assess the methodological quality of the studies. We applied the Jadad decision algorithm to select the best evidence review.

Results: Seven meta-analyses were included in this systematic review. The AMTASR scores of the studies ranged from 4 to 9 , with an average of 6 . Finally, Sun $\mathrm{H}$ et al was shown to represent the best evidence study. Sun $\mathrm{H}$ et al proposed that the unilateral kyphoplasty required less surgical time and consumed less cement, reduced cement leakage, and improved short-term general health compared with that of bilateral kyphoplasty.

Limitations: The AMTASR scores indicated that some of the included studies were of low quality. In addition, not all of the studies used the Grading of Recommendations Assessment, Development, and Evaluation (GRADE) level. When used, the GRADE level indicated that most of the results consisted of studies of low quality.

Conclusions: Unilateral kyphoplasty reduces the operative time, cement volume, and cement leakage rate compared with bilateral kyphoplasty. Therefore, we conclude that unilateral kyphoplasty is more advantageous, effective and safe, compared to bilateral kyphoplasty for the treatment of OVCFs.

Key words: Osteoporotic vertebral compression fracture, kyphoplasty, unilateral, bilateral, unipedicular, bipedicular, systematic review

Pain Physician 2019: 22:15-28 
steoporotic vertebral compression fractures (OVCFs) are very common in the elderly (1, 2) with most osteoporotic fractures occurring in the lower thoracic and thoracolumbar spine (3). The main sequelae of OVCFs are kyphosis and back pain caused by spinal misalignment (4). Therefore, the treatment for OVCFs should focus on pain relief and restoring the vertebral height, thereby improving the kyphosis $(5,6)$.

Balloon kyphoplasty is a percutaneous, minimally invasive surgery that has been found to be a safe and effective therapy for OVCFs (7). Currently, the standard technique for kyphoplasty is the bilateral approach using 2 balloon tamps (8). However, the unilateral approach has also been effective in producing mechanically sufficient support for OVCFs (9). Tohmeh et al (10) conducted a biomechanical trial examining the 2 approaches and proposed that both approaches could restore the vertebral body strength, stiffness, and height.

There were many meta-analyses and systematic reviews that compared the differences between unilateral and bilateral balloon kyphoplasty. However, their conclusions were discordant, which could confuse the decision makers when attempting to choose 1 suitable approach. Therefore, it is necessary to separate and distinguish the best evidence for treatment from the published literature.

This systematic review used the Jadad decision algorithm (11) to evaluate the methodology of the current meta-analyses or systematic reviews, and from this algorithm, the best evidence concerning unilateral versus bilateral balloon kyphoplasty was selected.

\section{Methods}

\section{Prior Design}

The design of this review was determined prior to the study. We assessed the quality of the current metaanalyses and systematic reviews for unilateral versus bilateral kyphoplasty for the treatment of OVCFs. We then selected the 1 meta-analysis or systematic review that had the best quality. Finally, we compared reported differences between unilateral and bilateral kyphoplasty for the treatment of OVCFs using the chosen best quality meta-analysis or systematic review as the standard. For our study, we followed the guidelines reported in the Preferred Reporting Items for Systematic Reviews and Meta-Analysis (PRISMA) Statement, which should increase both the reporting and methodological quality (12).
The selection criteria were determined. The inclusion criteria were as follows: a) meta-analyses and systematic reviews that compared unilateral kyphoplasty with bilateral kyphoplasty; b) meta-analyses that were based on randomized controlled trials (RCTs); and c) studies that had at least one outcome variable between the 2 groups. The exclusion criteria were a) metaanalyses and systematic reviews that included nonrandomized controlled trials; b) the systematic reviews without quantitative analysis; and c) narrative reviews. We modeled our study of overlapping meta-analyses and systematic reviews after the design was developed.

\section{Search Strategy}

We searched the electronic databases of PubMed, Embase and The Cochrane Library for literature. We included articles through Sept. 30, 2017. The articles were limited to meta-analyses and systematic reviews. Key words were kyphoplasty, unilateral kyphoplasty, bilateral kyphoplasty, unipedicular, bipedicular and osteoporotic vertebral compression fracture. The Boolean operators were used to link the key words, and only English language publications were included. We then reviewed the abstracts and read the full text of the articles that potentially met our inclusion criteria. We reviewed the references of the included articles. We manually searched the recent conference reports and papers over the last decade from the Peking University Health Science Library and consulted with 2 experts in the field for additional information. The search process was completed by 2 independent investigators, and discordant decisions were reviewed by a third investigator whose decision would be final.

\section{Data Extraction}

Two investigators independently extracted useful data in a standardized manner. The extracted data included the first author's name, searched databases, the publication date, the last search date, the publication status, the sensitivity analysis, language limitations, and heterogeneity. The data that were included were the outcome effect, statistical software, conflict of interest statement, and the Grading of Recommendations Assessment, Development, and Evaluation (GRADE) level.

\section{Assessment of Methodological Quality}

Two investigators used "A Measurement Tool to Assess Systematic Reviews" (AMTASR) (13) to evaluate the methodological quality of the meta-analyses and systematic reviews. The AMTASR contains 11 terms 
and has good face and content validity from which to measure the methodological quality of systematic reviews (13). For the evidence level of the included metaanalyses and systematic reviews, the investigators used the Oxford Levels of Evidence (14). The assessment was completed independently, and the divergence was resolved by a third-party decision.

\section{Assessment of Heterogeneity and GRADE Level}

We extracted the heterogeneity and GRADE level of each outcome effect in the meta-analyses and systematic review. The heterogeneity was tested using quantity $\mathrm{I}^{2}$, which provides consistency between trials in the meta-analyses and systematic reviews (15). The $\mathrm{I}^{2}$ value lies between $0 \%$ and $100 \%$. A value of $0 \%$ indicates that there was no observed heterogeneity, while larger values demonstrate increasing values of heterogeneity (15). The Cochrane Handbook for Systematic Reviews of Intervention (Version 5.1.0) assesses the heterogeneity using the range of the $\mathrm{I}^{2}$ value as follows: $0 \%-40 \%$ as "might not be important"; $40 \%-60 \%$ as "may represent moderate heterogeneity"; $50 \%-90 \%$ as "may represent substantial". The GRADE system was used to evaluate the quality of evidence for the outcomes in the included meta-analyses and systematic reviews. This system classifies the quality of evidence into 4 levels: high, moderate, low, and very low (16).

\section{Application of the Jadad Decision Algorithm}

The 1997 Jadad decision algorithm was used to help the reviewers who were making the decisions to understand discordance among reviews, guide their decisions, and help reviewers select the best evidence from discordant quantitative reviews (11). The algorithm contains a total of 9 steps. Decision-makers should judge every step and make selections from the included reviews. In our study, 3 investigators judged and made decisions independently, following the Jadad decision algorithm.

\section{RESULTS}

\section{Literature Characteristics}

We initially found 110 publications primarily from the electronic databases with 1 publication obtained through searching the references of the reviewed articles. Seven meta-analyses $(4,17-22)$ were included on the basis of the selection criteria previously described. The selection process and the reasons are described in detail in Fig. 1. The publication

Table 1. The databases searched by every meta-analysis.

\begin{tabular}{|l|c|c|c|c|c|c|c|c|}
\hline \multicolumn{1}{|c|}{ Author/Year } & Pubmed & Medline & Embase & $\begin{array}{c}\text { Cochrane } \\
\text { Library }\end{array}$ & CENTRAL $^{\mathbf{a}}$ & $\begin{array}{c}\text { Web of } \\
\text { Science }\end{array}$ & $\begin{array}{c}\text { Chinese } \\
\text { Databases }^{\mathbf{b}}\end{array}$ & Others $^{-1}$ \\
\hline Sun H (17) 2016 & + & + & + & + & - & + & - & - \\
\hline Feng H (18) 2015 & + & + & + & + & - & & + & + \\
\hline Chen H (4) 2014 & + & - & + & + & - & + & + & - \\
\hline Huang Z (19) 2014 & + & + & + & + & - & - & - & + \\
\hline Lin J (20) 2013 & + & + & + & - & + & - & - & + \\
\hline Yang L (21) 2013 & - & + & + & - & + & - & - & - \\
\hline Li L (22) 2013 & + & - & - & - & + & - & + \\
\hline
\end{tabular}

a: CENTRAL is the abbreviation of The Cochrane Central Register of Controlled Trials; b: Chinese Databases mean the electronic database where the literature was published in chinese; +: The database was searched; -: The database was not searched.

Table 2. The fundamental characteristics of the meta-analyses.

\begin{tabular}{|l|l|c|c|c||}
\hline \multicolumn{1}{|c|}{ Author/Year } & \multicolumn{1}{c|}{ Publication Journal } & Last Search Date & Publication Date & RCTs' numbers \\
\hline Sun H (17) 2016 & Pain Physician & June 2015 & June 2016 & 6 \\
\hline Feng H (18) 2015 & Journal of Orthopaedic Research & January 2015 & July 2015 & 12 \\
\hline Chen H (4) 2014 & Orthopedics & April 2013 & September 2014 & 14 \\
\hline Huang Z (19) 2014 & Clinical Orthopaedics and Related Research & June 2013 & June 2014 & 5 \\
\hline Lin J (20) 2013 & Pain Physician & July 2012 & October 2012 & 3 \\
\hline Yang L (21) 2013 & Pain Physician & September 2012 & February 2013 & 4 \\
\hline Li L (22) 2013 & Chinese Medical Journal (English) & March 2013 & October 2013 & 7 \\
\hline
\end{tabular}




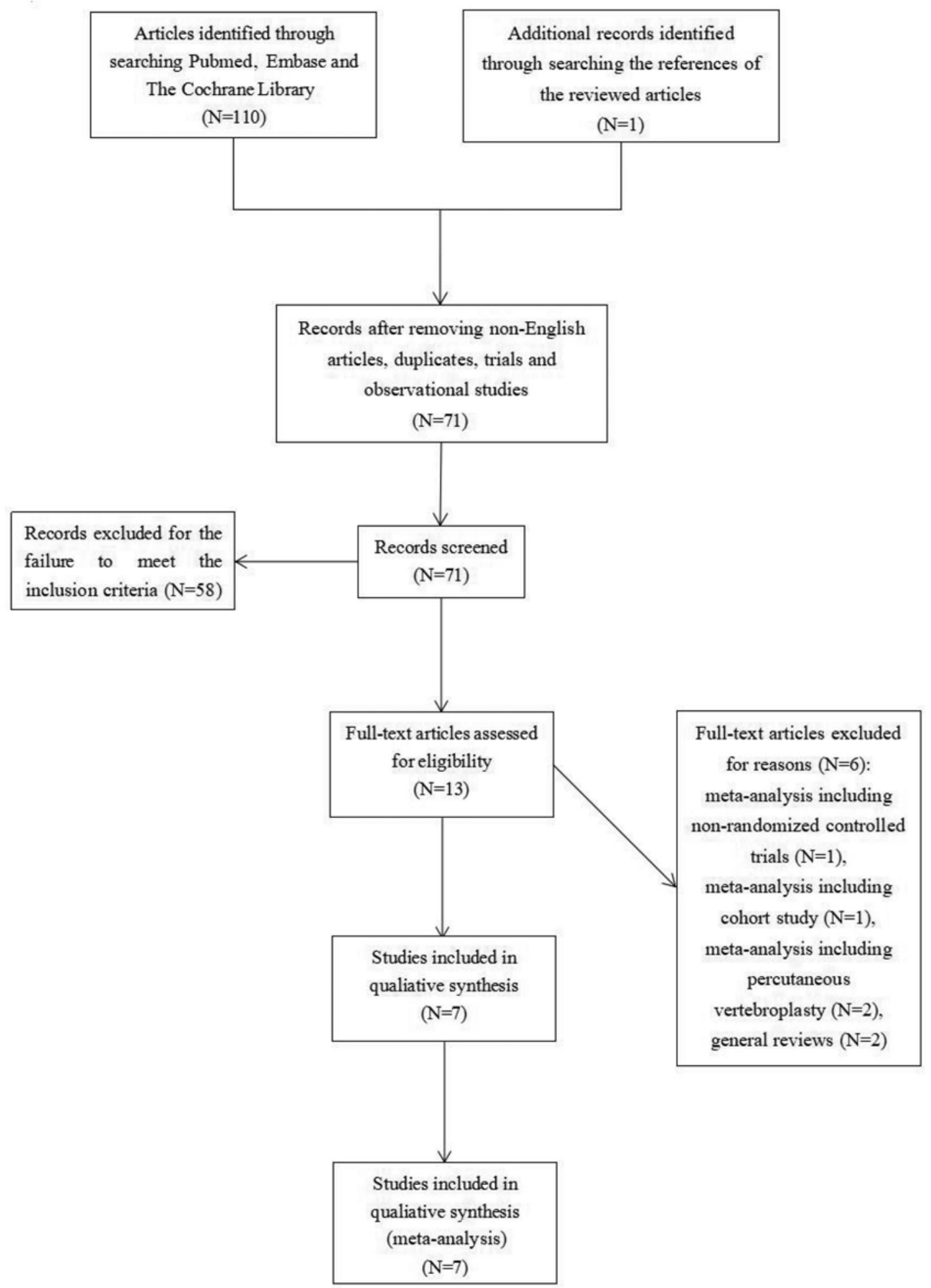

Fig. 1. Flow chart of selection of meta-analyses and systematic reviews following the PRISMA statement. 
date of the 7 meta-analyses ranged from February 2013 to January 2016. The number of original studies in the meta-analyses ranged from 3 to 13, with an average of 7 . The fundamental characteristics of the 7 meta-analyses are described in Tables 1 and 2 . The primary trials included in the meta-analyses are shown in Table 3.

\section{Search Methodology}

We extracted the databases, language limitation, publication status, sensitivity analysis and the software for analysis from the included meta-analyses (Table 4). All the meta-analyses involved a comprehensive literature search, and Chinese databases were searched in 3 studies $(4,18,22)$. PubMed, Medline and Embase were the most common databases used for the search. One study (22) used the STATA 12.0 software (Stata Corporation, College Station, TX, USA) for the statistical analysis, while the remaining studies $(4,17-21)$ used the Revman software (The Cochrane Collaboration, Copenhagen, Denmark) (Table 4).

\section{Methodological Quality}

All 7 studies were evaluated for methodological quality. Each study included RCTs (Table 3). The AMTASR scores for the studies ranged from 4 to 9, the average of which was 6 (Table 5). Yang $L$ et al (21) achieved the highest AMTASR score. We used the Oxford Levels of Evidence (15) to evaluate the studies. Three studies $(4,18,22)$ met Level II evidence criteria, while the remaining studies met Level I evidence criteria (Table 4). The meta-analysis by Yang $L$ et al (21) represented the highest quality study.

\section{Heterogeneity and GRADE Level}

All studies assessed the heterogeneity of the outcome effects with the statistical quantity 12 (Table 6). Four studies $(17,19,21,22)$ centered their sensitivity analysis around their outcome effects (Table 4). Only 3 studies $(4,17,18)$ used the GRADE level, which can be found in Table 6.

\section{Results of the Jadad Decision Algorithm}

From the 7 studies, the final decision regarding the best evidence study was made by the 3 investigastudies compared unilateral to bilateral kyphoplasty for the treatment of OVCFs. However, the selection criteria of the 7 studies differed. The 3 investigators then reviewed the 7 studies with respect to publication tors using the Jadad decision algorithm. Each of the 7

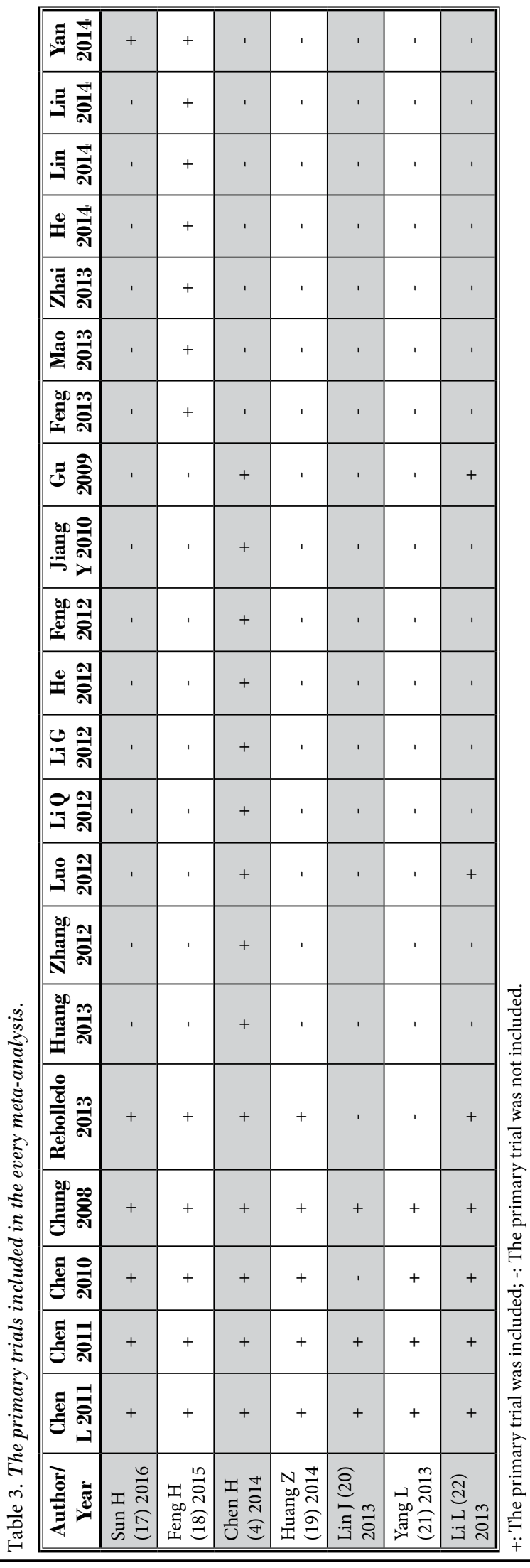

www.painphysicianjournal.com 
Table 4. The methodological messages of the meta-analyses.

\begin{tabular}{|c|c|c|c|c|c|c|c|}
\hline Author/Year & $\begin{array}{c}\text { Design of } \\
\text { Included Studies } \\
\end{array}$ & $\begin{array}{l}\text { Level of } \\
\text { Evidence }\end{array}$ & $\begin{array}{c}\text { Language } \\
\text { Limitation } \\
\end{array}$ & $\begin{array}{c}\text { Publication } \\
\text { Status }\end{array}$ & $\begin{array}{c}\text { Sensitivity } \\
\text { Analysis }\end{array}$ & Software & $\begin{array}{c}\text { GRADE } \\
\text { Use }\end{array}$ \\
\hline Sun H (17) 2016 & RCT & I & English & Published & YES & Revman 5.3 & YES \\
\hline Feng H (18) 2015 & RCT & II & English \& Chinese & Published & NO & Revman 5.2 & NO \\
\hline Chen H (4) 2014 & RCT & II & No & Published & NO & Revman 5.2 & YES \\
\hline Huang Z (19) 2014 & RCT & $\mathrm{I}$ & English & Published & YES & Revman 5.1 & YES \\
\hline Lin J (20) 2013 & RCT & I & No & Published & NO & Revman 5.1 & NO \\
\hline Yang L (21) 2013 & RCT & I & No & Published & YES & Revman 5.1 & $\mathrm{NO}$ \\
\hline Li L (22) 2013 & RCT & II & No & Published & YES & STATA 12.0 & $\mathrm{NO}$ \\
\hline
\end{tabular}

Table 5. AMTASR scores of every meta-analysis.

\begin{tabular}{|c|c|c|c|c|c|c|c|}
\hline Items & $\begin{array}{c}\text { Sun H } \\
\text { (17) } 2016\end{array}$ & $\begin{array}{c}\text { Feng } H \\
\text { (18) } 2015\end{array}$ & $\begin{array}{c}\text { Chen H } \\
\text { (4) } 2014\end{array}$ & $\begin{array}{c}\text { Huang Z } \\
\text { (19) } 2014\end{array}$ & $\begin{array}{c}\text { Lin J (20) } \\
2013 \\
\end{array}$ & $\begin{array}{c}\text { Yang } L \\
(21) 2013\end{array}$ & $\begin{array}{c}\text { Li L (22) } \\
2013\end{array}$ \\
\hline Was an 'a priori' design provided? & 0 & 0 & 0 & 0 & 0 & 1 & 0 \\
\hline $\begin{array}{l}\text { Was there duplicate study selection and } \\
\text { data extraction? }\end{array}$ & 1 & 1 & 1 & 1 & 1 & 1 & 1 \\
\hline $\begin{array}{l}\text { Was a comprehensive literature search } \\
\text { performed? }\end{array}$ & 0 & 0 & 0 & 0 & 0 & 1 & 0 \\
\hline $\begin{array}{l}\text { Was the status of publication (i.e. grey } \\
\text { literature) used as an inclusion criterion? }\end{array}$ & 0 & 0 & 0 & 0 & 0 & 0 & 0 \\
\hline $\begin{array}{l}\text { Was a list of studies (included and } \\
\text { excluded) provided? }\end{array}$ & 1 & 1 & 0 & 1 & 0 & 1 & 1 \\
\hline $\begin{array}{l}\text { Were the characteristics of the included } \\
\text { studies provided? }\end{array}$ & 1 & 1 & 1 & 1 & 1 & 1 & 0 \\
\hline $\begin{array}{l}\text { Was the scientific quality of the included } \\
\text { studies assessed and documented? }\end{array}$ & 1 & 1 & 1 & 1 & 1 & 1 & 0 \\
\hline $\begin{array}{l}\text { Was the scientific quality of the } \\
\text { included studies used appropriately in } \\
\text { formulating conclusions? }\end{array}$ & 1 & 1 & 1 & 1 & 0 & 1 & 0 \\
\hline $\begin{array}{l}\text { Were the methods used to combine the } \\
\text { findings of studies appropriate? }\end{array}$ & 1 & 1 & 1 & 1 & 1 & 1 & 1 \\
\hline $\begin{array}{l}\text { Was the likelihood of publication bias } \\
\text { assessed? }\end{array}$ & 0 & 1 & 0 & 0 & 0 & 1 & 1 \\
\hline Was the conflict of interest stated? & 1 & 1 & 0 & 0 & 0 & 0 & 0 \\
\hline Total & 7 & 8 & 4 & 6 & 4 & 9 & 4 \\
\hline
\end{tabular}

status, methodological quality, language restrictions, and data analysis of individual patients. No study was based on the data analysis of individual patients. Each study included the published literature. Three studies (17-19) restricted the publication language, 2 of which only included English studies and 1 included English and Chinese studies. Three studies $(4,18,22)$ included Chinese as part of their publication language. The methodological quality of the studies was evaluated by the 3 investigators, and the meta-analysis of more randomized controlled trials performed by Sun $\mathrm{H}$ et al
(17) was chosen as having the best evidence quality. The outcome effects of the 7 studies are shown in Fig. 2. The Jadad decision algorithm is shown in Fig. 3.

Sun $\mathrm{H}$ et al (17) reported that unilateral kyphoplasty required less surgical time $(\mathrm{MD}=-23.19, P<$ $0.00001)$, less cement usage (MD $=-2.07, P<0.00001)$, reduced cement leakage $(\mathrm{RR}=0.59, P<0.05)$ and improved short-term general health (MD $=1.48, P<0.05)$ compared with that of bilateral kyphoplasty. They found no significant difference between unilateral and bilateral kyphoplasty in the Visual Analog Scale (VAS) 
scores (short-term and long-term), Oswestry Disability Index (ODI) scores (mid-term and long-term), degree of kyphotic angle reduction, restoration rate of anterior vertebral height, vertebral height loss rate, the number and incidence rate of postoperative adjacent-level fractures, or in other assessments made for the 36-Item Short Form Health Survey (SF-36) parameters (shortterm and long-term).

\section{Discussion}

Meta-analyses and systematic reviews were confirmed as the evidence with the highest quality in evidence-based medicine (23). Seven meta-analyses $(4,17-$ 22) were available to compare the outcome effect and safety between the unilateral and bilateral kyphoplasty for OVCFs, but they proposed different conclusions. For example, 2 meta-analyses $(4,17)$ concluded that the unilateral approach reduced the cement leakage, while the others (18-22) disagreed with the significant difference between the 2 approaches in the cement leakage. These controversial conclusions confused the clinical decision makers and did not standardize the therapy effectively (11).

Jadad et al (11) proposed the sources of discordance among the meta-analyses as follows: the clinical question, study selection and inclusion criteria, data extraction, assessment of study quality, assessment of the ability to combine studies and statistical methods for

Table 6. The heterogeneity and GRADE level of every outcome effect in the meta-analyses.

\begin{tabular}{|c|c|c|c|c|c|}
\hline Author/Year & \multirow{2}{*}{\begin{tabular}{|l|} 
The Outcome Effects \\
operative time \\
\end{tabular}} & & \multicolumn{2}{|c|}{ Heterogeneity } & \multirow{2}{*}{$\begin{array}{l}\text { GRADE } \\
\text { High }\end{array}$} \\
\hline \multirow{27}{*}{ Sun H (17) 2016} & & & $P=0.002$ & $\mathrm{I}^{2}=77 \%$ & \\
\hline & cement volume & & $P=0.43$ & $\mathrm{I}^{2}=0 \%$ & High \\
\hline & short-term VAS scores & & $P=0.08$ & $\mathrm{I}^{2}=55 \%$ & Very Low \\
\hline & long-term VAS scores & & $P=0.33$ & $\mathrm{I}^{2}=13 \%$ & Low \\
\hline & mid-term ODI scores & & $P=0.45$ & $\mathrm{I}^{2}=0 \%$ & Low \\
\hline & long-term ODI scores & & $P=0.37$ & $\mathrm{I}^{2}=0 \%$ & Low \\
\hline & cement leakage & & $P=0.28$ & $\mathrm{I}^{2}=22 \%$ & Low \\
\hline & postoperative adjacent-level fracture & & $P=0.50$ & $\mathrm{I}^{2}=0 \%$ & Moderate \\
\hline & kyphotic angle reduction & & $P=-\mathrm{c}$ & $\mathrm{I}^{2}=93 \%$ & Very Low \\
\hline & anterior vertebral height restoration & & $P=-$ & $\mathrm{I}^{2}=88 \%$ & Very Low \\
\hline & vertebral height loss & & $P=-$ & $\mathrm{I}^{2}=68 \%$ & Very Low \\
\hline & \multirow{8}{*}{ 36-Item Short Form Health Survey parameters (short-term ) } & $\mathrm{PF}$ & $P=0.76$ & $\mathrm{I}^{2}=0 \%$ & Low \\
\hline & & $\mathrm{RP}$ & $P=0.08$ & $\mathrm{I}^{2}=67 \%$ & Very Low \\
\hline & & $\mathrm{BP}$ & $P=0.59$ & $\mathrm{I}^{2}=0 \%$ & Low \\
\hline & & $\mathrm{GH}$ & $P=0.36$ & $\mathrm{I}^{2}=0 \%$ & Low \\
\hline & & VT & $P=0.50$ & $\mathrm{I}^{2}=0 \%$ & Low \\
\hline & & SF & $P=0.96$ & $\mathrm{I}^{2}=0 \%$ & Low \\
\hline & & $\mathrm{RE}$ & $P=0.29$ & $\mathrm{I}^{2}=9 \%$ & Low \\
\hline & & $\mathrm{MH}$ & $P=0.72$ & $\mathrm{I}^{2}=0 \%$ & Low \\
\hline & \multirow{8}{*}{ 36-Item Short Form Health Survey parameters (long-term ) } & $\mathrm{PF}$ & $P=0.87$ & $\mathrm{I}^{2}=0 \%$ & Low \\
\hline & & $\mathrm{RP}$ & $P=0.12$ & $\mathrm{I}^{2}=58 \%$ & Very Low \\
\hline & & $\mathrm{BP}$ & $P=0.54$ & $\mathrm{I}^{2}=0 \%$ & Low \\
\hline & & $\mathrm{GH}$ & $P=0.97$ & $\mathrm{I}^{2}=0 \%$ & Low \\
\hline & & $\mathrm{VT}$ & $P=0.20$ & $\mathrm{I}^{2}=38 \%$ & Low \\
\hline & & SF & $P=0.98$ & $\mathrm{I}^{2}=0 \%$ & Low \\
\hline & & $\mathrm{RE}$ & $P=0.77$ & $\mathrm{I}^{2}=0 \%$ & Low \\
\hline & & $\mathrm{MH}$ & $P=0.85$ & $\mathrm{I}^{2}=0 \%$ & Low \\
\hline
\end{tabular}


Pain Physician: January/February 2019: 22:15-28

Table 6 con't. The heterogeneity and GRADE level of every outcome effect in the meta-analyses.

\begin{tabular}{|c|c|c|c|c|c|}
\hline Author/Year & \multirow{2}{*}{$\begin{array}{l}\text { The Outcome Effects } \\
\text { short-term VAS scores }\end{array}$} & & \multicolumn{2}{|c|}{ "Heterogeneity } & \multirow{2}{*}{$\begin{array}{l}\text { GRADE } \\
-\end{array}$} \\
\hline \multirow{32}{*}{ Feng H (18) 2015} & & & $P=0.84$ & $\mathrm{I}^{2}=0 \%$ & \\
\hline & mid-term VAS scores & & $P=0.82$ & $\mathrm{I}^{2}=0 \%$ & - \\
\hline & long-term VAS scores & & $P=0.73$ & $\mathrm{I}^{2}=0 \%$ & - \\
\hline & short-term ODI scores & & $P=0.21$ & $\mathrm{I}^{2}=36 \%$ & - \\
\hline & operative time & & $P=0.33$ & $\mathrm{I}^{2}=14 \%$ & - \\
\hline & cement volumn & & $P=0.11$ & $\mathrm{I}^{2}=44 \%$ & - \\
\hline & kyphotic angle reduction & & $P=0.001$ & $\mathrm{I}^{2}=85 \%$ & - \\
\hline & Cobb's angle recovery & & $P=0.11$ & $\mathrm{I}^{2}=50 \%$ & - \\
\hline & vertebral height loss & & $P=0.85$ & $\mathrm{I}^{2}=0 \%$ & - \\
\hline & vertebral height restoration & & $P<0.00001$ & $\mathrm{I}^{2}=94 \%$ & - \\
\hline & short-term anterior vertebral height restoration & & $P=0.84$ & $\mathrm{I}^{2}=0 \%$ & - \\
\hline & long-term anterior vertebral height restoration & & $P=0.30$ & $\mathrm{I}^{2}=18 \%$ & - \\
\hline & short-term middle vertebral height restoration & & $P=0.97$ & $\mathrm{I}^{2}=0 \%$ & - \\
\hline & long-term middle vertebral height restoration & & $P=0.85$ & $\mathrm{I}^{2}=0 \%$ & - \\
\hline & cement leakage & & $P=0.50$ & $\mathrm{I}^{2}=0 \%$ & - \\
\hline & postoperative adjacent-level fracture & & $P=0.49$ & $\mathrm{I}^{2}=0 \%$ & - \\
\hline & \multirow{8}{*}{ 36-Item Short Form Health Survey parameters (short-term ) } & $\mathrm{PF}$ & $P=-$ & $\mathrm{I}^{2}=0 \%$ & - \\
\hline & & $\mathrm{RP}$ & $P=-$ & $\mathrm{I}^{2}=67 \%$ & - \\
\hline & & $\mathrm{BP}$ & $P=-$ & $\mathrm{I}^{2}=9 \%$ & - \\
\hline & & $\mathrm{GH}$ & $P=-$ & $\mathrm{I}^{2}=0 \%$ & - \\
\hline & & VT & $P=-$ & $\mathrm{I}^{2}=0 \%$ & - \\
\hline & & SF & $P=-$ & $\mathrm{I}^{2}=0 \%$ & - \\
\hline & & $\mathrm{RE}$ & $P=-$ & $\mathrm{I}^{2}=9 \%$ & - \\
\hline & & $\mathrm{MH}$ & $P=-$ & $\mathrm{I}^{2}=0 \%$ & - \\
\hline & \multirow{8}{*}{ 36-Item Short Form Health Survey parameters (long-term ) } & $\mathrm{PF}$ & $P=-$ & $\mathrm{I}^{2}=0 \%$ & - \\
\hline & & $\mathrm{RP}$ & $P=-$ & $\mathrm{I}^{2}=62 \%$ & - \\
\hline & & $\mathrm{BP}$ & $P=-$ & $\mathrm{I}^{2}=0 \%$ & - \\
\hline & & $\mathrm{GH}$ & $P=-$ & $\mathrm{I}^{2}=0 \%$ & - \\
\hline & & VT & $P=-$ & $\mathrm{I}^{2}=15 \%$ & - \\
\hline & & SF & $P=-$ & $\mathrm{I}^{2}=0 \%$ & - \\
\hline & & $\mathrm{RE}$ & $P=-$ & $\mathrm{I}^{2}=0 \%$ & - \\
\hline & & $\mathrm{MH}$ & $P=-$ & $\mathrm{I}^{2}=0 \%$ & - \\
\hline \multirow{11}{*}{ Chen H (4) 2014} & short-term VAS scores & & $P=0.58$ & $\mathrm{I}^{2}=0 \%$ & Low \\
\hline & long-term VAS scores(1 year) & & $P=0.98$ & $\mathrm{I}^{2}=0 \%$ & Low \\
\hline & long-term VAS scores(2 year) & & $P=0.50$ & $\mathrm{I}^{2}=0 \%$ & Low \\
\hline & short-term ODI scores & & $P=0.06$ & $\mathrm{I}^{2}=72 \%$ & Very Low \\
\hline & long-term ODI scores & & $P<0.0001$ & $\mathrm{I}^{2}=91 \%$ & Very Low \\
\hline & anterior vertebral height Restoration & & $P=0.54$ & $\mathrm{I}^{2}=0 \%$ & Low \\
\hline & middle vertebral height Restoration & & $P=0.25$ & $\mathrm{I}^{2}=25 \%$ & Low \\
\hline & kyphotic angle reduction & & $P=0.08$ & $\mathrm{I}^{2}=42 \%$ & Low \\
\hline & operative time & & $P=0.13$ & $\mathrm{I}^{2}=32 \%$ & Low \\
\hline & cement volumn & & $P=0.10$ & $\mathrm{I}^{2}=38 \%$ & Low \\
\hline & cement leakage & & $P=0.23$ & $\mathrm{I}^{2}=27 \%$ & Low \\
\hline
\end{tabular}


Unilateral vs. Bilateral Balloon Kyphoplasty for OVCF

Table 6 con't. The heterogeneity and GRADE level of every outcome effect in the meta-analyses.

\begin{tabular}{|c|c|c|c|c|}
\hline \multirow{2}{*}{ Author/Year } & \multirow{2}{*}{\begin{tabular}{|l|} 
The Outcome Effects \\
short-term VAS score
\end{tabular}} & \multicolumn{2}{|c|}{ Heterogeneity } & \multirow{2}{*}{$\begin{array}{l}\text { GRADE } \\
\text { Low }\end{array}$} \\
\hline & & $P=0.77$ & $\mathrm{I}^{2}=0 \%$ & \\
\hline \multirow{8}{*}{ Huang Z (19) 2014} & long-term VAS score & $P=0.97$ & $\mathrm{I}^{2}=0 \%$ & Low \\
\hline & mid-term ODI scores & $P=-$ & $I^{2}=-$ & Very Low \\
\hline & long-term ODI scores & $P=-$ & $\mathrm{I}^{2}=-$ & Very Low \\
\hline & cement leakage & $P=-$ & $I^{2}=-$ & Low \\
\hline & adjacent-level fractures & $P=0.20$ & $\mathrm{I}^{2}=39 \%$ & Low \\
\hline & operation time & $P=0.61$ & $\mathrm{I}^{2}=0 \%$ & High \\
\hline & kyphosis angle reduction & $P=-$ & $\mathrm{I}^{2}=85 \%$ & Low \\
\hline & anterior vertebral body height restoration & $P=-$ & $\mathrm{I}^{2}=91 \%$ & Very Low \\
\hline \multirow{6}{*}{ Lin J (20) 2013} & pre-operative VAS scores & $P=0.17$ & $I^{2}=46 \%$ & - \\
\hline & short-term VAS scores & $P=0.93$ & $\mathrm{I}^{2}=0 \%$ & - \\
\hline & long-term VAS scores & $P=0.63$ & $\mathrm{I}^{2}=0 \%$ & - \\
\hline & operative time & $P=0.27$ & $\mathrm{I}^{2}=17 \%$ & - \\
\hline & cement volume & $P=0.86$ & $\mathrm{I}^{2}=0 \%$ & - \\
\hline & cement leakage & $P=0.16$ & $\mathrm{I}^{2}=45 \%$ & - \\
\hline \multirow{6}{*}{ Yang L (21) 2013} & operative time & $P=0.39$ & $\mathrm{I}^{2}=0 \%$ & - \\
\hline & short-term VAS scores & $P=0.62$ & $\mathrm{I}^{2}=0 \%$ & - \\
\hline & long-term VAS scores & $P=0.61$ & $\mathrm{I}^{2}=0 \%$ & - \\
\hline & adjacent-level fractures & $P=0.22$ & $\mathrm{I}^{2}=34 \%$ & - \\
\hline & cement leakage & $P=0.25$ & $\mathrm{I}^{2}=28 \%$ & - \\
\hline & vertebral height loss & $P=0.08$ & $\mathrm{I}^{2}=68 \%$ & - \\
\hline \multirow{12}{*}{ Li L (22) 2013} & pre-operative VAS scores & $P=-$ & $\mathrm{I}^{2}=0 \%$ & - \\
\hline & short-term VAS scores ( $\leq 3$ months) & $P=-$ & $\mathrm{I}^{2}=0 \%$ & - \\
\hline & long-term VAS scores ( $\geq 1$ year) & $P=-$ & $\mathrm{I}^{2}=0 \%$ & - \\
\hline & pre-operative ODI scores & $P=0.09$ & $\mathrm{I}^{2}=57.3 \%$ & - \\
\hline & short-term ODI scores ( $\leq 3$ months) & $P=-$ & $I^{2}=-$ & - \\
\hline & long-term ODI scores ( $\geq 1$ year) & $P=-$ & $I^{2}=-$ & - \\
\hline & Cement volume & $P=0.13$ & $\mathrm{I}^{2}=50.4 \%$ & - \\
\hline & operative time & $P=0.00$ & $\mathrm{I}^{2}=94.7 \%$ & - \\
\hline & preoperative kyphosis angle & $P=0.46$ & $\mathrm{I}^{2}=0.0 \%$ & - \\
\hline & kyphosis angle reduction & $P=0.89$ & $\mathrm{I}^{2}=0.0 \%$ & - \\
\hline & kyphosis angle restoration & $P=0.00$ & $\mathrm{I}^{2}=94.3 \%$ & - \\
\hline & cement leakage & $P=-$ & $\mathrm{I}^{2}=39.9 \%$ & - \\
\hline
\end{tabular}

c: “-”means that this data was not mentioned in the reviews. VAS, Visual Analog Scale; ODI,Oswestry Disability Index; PF, physical function; RP, role physical; BP, bodily pain; GH, general health; VT, vitality; SF, social function; RE, role emotional; $\mathrm{MH}$, mental health

data synthesis. They also offered a decision algorithm to select the best evidence reviews from discordant reviews (11), which were commonly used in selecting meta-analyses and systematic reviews (24-29). We applied the algorithm in 7 meta-analyses. Feng $\mathrm{H}$ et al (18), Chen $\mathrm{H}$ et al (4) and Li L et al (22) included tri- als written in Chinese, which were published locally in China, reducing publication bias and random error (11) for inclusion of more studies to some extent. However, these 3 studies $(4,18,22)$ were assessed as level II according to the Oxford Levels of Evidence (15). Although the AMTASR scores of Yang $L$ et al were the highest among 
Pain Physician: January/February 2019: 22:15-28

\begin{tabular}{|c|c|c|c|c|c|c|c|c|}
\hline \multicolumn{2}{|c|}{ Terescoen Effocts } & $\frac{\pi}{5} \frac{0}{6}$ & ${ }_{\frac{0}{5}}^{\frac{n}{8}} \frac{n}{8}$ & $\frac{z}{\frac{E}{0}} \frac{\vec{x}}{8}$ & $\frac{N}{\underline{y}} \frac{\pi}{2}$ & $\frac{5}{3} \frac{m}{8}$ & है है & $=\frac{m}{8}$ \\
\hline \multicolumn{9}{|c|}{ epentive tirse } \\
\hline \multicolumn{9}{|c|}{ cenarat velunir } \\
\hline \multicolumn{9}{|c|}{ Prepentine VAS seures } \\
\hline \multicolumn{9}{|c|}{ stormenne VAS scoxes } \\
\hline \multicolumn{9}{|c|}{ mibrem VAS reoves } \\
\hline \multicolumn{9}{|c|}{ Ieptem Vas sesres } \\
\hline \multicolumn{9}{|c|}{ preoperabive OOT skons } \\
\hline \multicolumn{9}{|c|}{ Simt-Mm: COI isores } \\
\hline \multicolumn{9}{|c|}{ midsum 001 sores } \\
\hline \multicolumn{9}{|c|}{ boctenn COX woves } \\
\hline \multicolumn{9}{|c|}{ cenarat leakage } \\
\hline \multicolumn{9}{|c|}{ 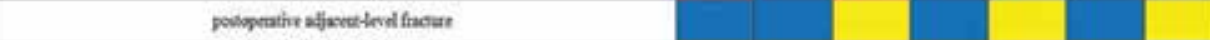 } \\
\hline \multicolumn{9}{|c|}{ Foopraive byposis angle } \\
\hline \multicolumn{9}{|c|}{ 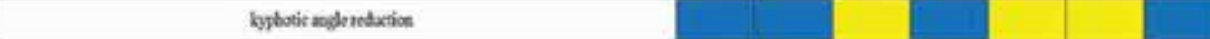 } \\
\hline \multicolumn{9}{|c|}{ kpplosis mple neteration } \\
\hline \multicolumn{9}{|c|}{ Cobbinandernevery } \\
\hline \multicolumn{9}{|c|}{ antebor veschul height restaration } \\
\hline \multicolumn{9}{|c|}{ 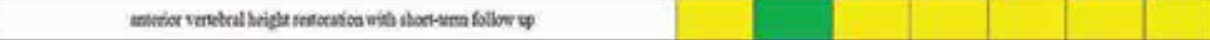 } \\
\hline \multicolumn{9}{|c|}{ 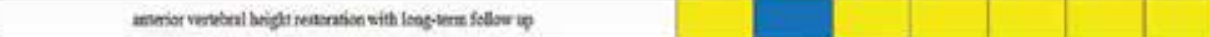 } \\
\hline \multicolumn{9}{|c|}{ midfe ventikal beifta settoation } \\
\hline \multicolumn{9}{|c|}{ 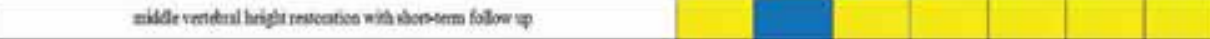 } \\
\hline \multicolumn{9}{|c|}{ 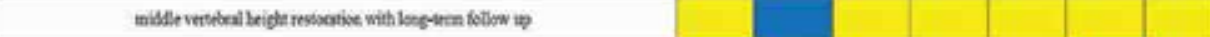 } \\
\hline \multicolumn{9}{|c|}{ 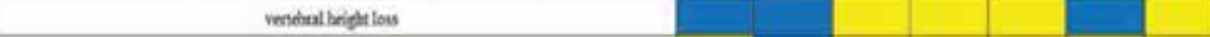 } \\
\hline venitral tei & & & & & & & & \\
\hline & FF & & & & & & & \\
\hline & $\mathbf{k P}$ & & & & & & & \\
\hline & a? & & & & & & & \\
\hline 36-tien Stort Form Hold Savoy peranen & CH & & & & & & & \\
\hline (blantera) & vT & & & & & & & \\
\hline & \$F & & & & & & & \\
\hline & RE & & & & & & & \\
\hline & sat & & & & & & & \\
\hline & WF & & & & & & & \\
\hline & op & & & & & & & \\
\hline & $\mathrm{BP}$ & & & & & & & \\
\hline 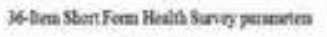 & CH & & & & & & & \\
\hline (lonptam) & vT & & & & & & & \\
\hline & St & & & & & & & \\
\hline & RE & & & & & & & \\
\hline & $\mathbf{M H}$ & & & & & & & \\
\hline Fvours thilemal & Favours Bleicral & & No Diffin & & & & Not Repet & \\
\hline
\end{tabular}

Fig. 2. The

outcome effects

of the meta

analyses.

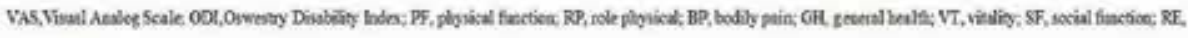
rolitenocionat Mat, netral benith 


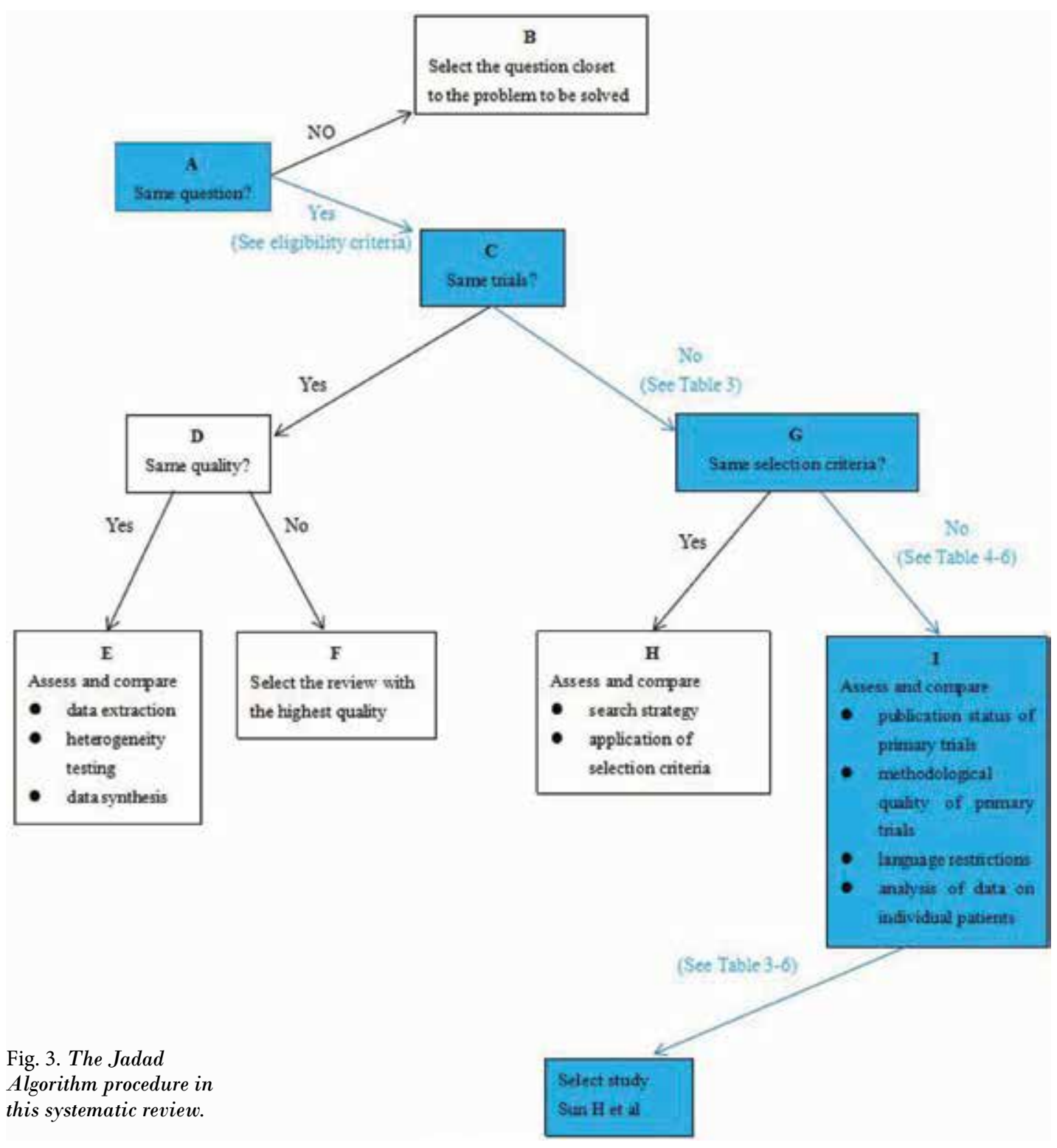

the studies, we finally selected the study of Sun $\mathrm{H}$ et al (17) as the study with the best evidence for the inclusion of more trials and providing the most current evidence.

This is the first systematic review of the overlapping meta-analyses to compare the unilateral approach to the bilateral approach in kyphoplasty for OVCFs. Sun $\mathrm{H}$ et al (17) was shown to represent the best evidence study. According to the meta-analysis of Sun $\mathrm{H}$ et al (17), we concluded that unilateral kyphoplasty could reduce the operation time, cement volume, and cement leakage rate compared to that of bilateral kyphoplasty, while there were no differences in VAS scores, ODI scores, radiographic assessment, adjacent-level fracture rate and most of the SF-36 subscale scores.

Osteoporosis is characterized by the systemic impairment of bone mass, strength, and microarchitecture, which increases the propensity of fragility fractures (30). OVCFs are very common in elderly people, causing intractable pain, kyphosis and greatly impairing the quality of a patient's life $(1,2,4,31-33)$. 
Balloon kyphoplasty is a minimally invasive operation used in the treatment of patients with OVCFs who have no improvement after 4 weeks of conservative therapy (34-36); it involves the insertion of the balloon plate into the vertebral body, followed by the injection of cement for the fixation of the vertebral body. Balloon kyphoplasty can provide rapid and constant pain relief, reduce the kyphosis deformity and improve the quality of life; thus, it has been regarded as one of the standard operations during the last decade $(5,7,18,20,37,38)$. There are 2 approaches in balloon kyphoplasty, namely, unilateral and bilateral approaches $(4,17-22,39,40)$. Steinmann et al (9) planned a cadaveric study comparing the biomechanics of unilateral kyphoplasty to bilateral kyphoplasty. The results indicated that there were no differences between the two approaches in the restoration of vertebral body strength, stiffness, and height in OVCFs. However, the complications between the 2 approaches were the main points that attracted the attention of those making the decisions. Cement leakage and adjacent vertebral fracture are very serious and common complications. The leakage rate was reported to be approximately $18.4 \%$ in percutaneous balloon kyphoplasty (41), and the adjacent vertebral fracture rate ranged from $7.9 \%$ to $24 \%(41,42)$. The excessive cement volume was also thought to be an important risk factor for the cement leakage and adjacent vertebral fractures $(21,41,43)$, although Belkoff et al (44) proposed that only $2 \mathrm{~mL}$ of bone cement was adequate to restore strength. When the cement volume increased, the risk of cement leakage and the adjacent vertebral fractures increased (41). Lin et al (41) and Kolb et al (45) also proposed that the unilateral approach might cause the uneven distribution of the bone cement and change the biomechanics of the vertebral bodies resulting in increased compression of the adjacent vertebral bodies and cement leakage. In addition to the factors mentioned above, an intravertebral cleft, cortical disruption and low cement viscosity were also risk factors for cement leakage (43). These factors interacted with each other and affected the results between the 2 approaches. Our systematic review came to the final conclusion that the unilateral approach reduced the cement volume and cement leakage. Additionally, no significant difference was found in adjacent vertebral fractures between the 2 approaches. Our systematic review also found no significant differences in VAS scores, ODI scores, radiographic assessment, and most of the SF- 36 subscale scores, which means the efficacy of the 2 approaches were comparable.

Some limitations existed in our systematic review. First, the AMTASR scores indicated that some of the included studies were of low quality. Most of the included studies did not provide the prior design and did not perform a comprehensive literature search, which could have resulted in failure to access the gray literature. Second, not all the studies used the GRADE level. Moreover, the level showed that most of the outcomes were associated with evidence of low quality.

\section{Conclusion}

This systematic review of overlapping meta-analyses indicated that unilateral kyphoplasty could reduce the operation time, cement volume and the cement leakage rate compared to that of bilateral kyphoplasty. This conclusion was the evidence of the best quality. On the basis of this outcome, we concluded that unilateral kyphoplasty was more advantageous than bilateral kyphoplasty in the efficacy and safety of OVCF treatment.

\section{Acknowledgments}

The authors wish to thank Professor Huang Yueqin from the Peking University Sixth Hospital and Professor Guo Yi from the Wuhan University for their advice in preparation of this manuscript.

Author Contributions: Cui Zhiyong and Tian Yun designed the aim and literature criteria of this review. Cui Zhiyong, Feng Hui and Yang Zhongwei searched the databases and selected out the available literature. Cui Zhiyong, Tian Yun and Liu Zhaorui analyzed the method results. All the authors have read the manuscript. 


\section{References}

1. Kumar K, Verma A, Wilson J, LaFontaine A. Vertebroplasty in osteoporotic spine fractures: A quality of life assessment. Can J Neurol Sci 2005; 4:487-495.

2. Johnell O, Kanis J. An estimate of the worldwide prevalence and disability associated with osteoporotic fractures. Osteoporosis International 2006; 12:1726-1733.

3. Ge Z, Ma R, Chen Z, Zhang H, Ding $\mathrm{H}$, Liang S, Suo Z. Uniextrapedicular kyphoplasty for the treatment of thoracic osteoporotic vertebral fractures. Orthopedics 2013; 8:e1020-e1024.

4. Chen $\mathrm{H}$, Tang $\mathrm{P}$, Zhao $\mathrm{Y}$, Gao $\mathrm{Y}$, Wang $\mathrm{Y}$. Unilateral versus bilateral balloon kyphoplasty in the treatment of osteoporotic vertebral compression fractures. Orthopedics 2014; 9:e828-e835.

5. Frankel B, Monroe T, Wang C. Percutaneous vertebral augmentation: An elevation in adjacent-level fracture risk in kyphoplasty as compared with vertebroplasty. The Spine Journal 2007; 7:575-582.

6. Papaioannou A, Watts N, Kendler D, Yuen CK, Adachi J, Ferko N.. Diagnosis and management of vertebral fractures in elderly adults. Am J Med 2002; 3:220-228.

7. Rhyne A, Banit D, Laxer E, Odum S, Nussman D. Kyphoplasty: Report of eighty-two thoracolumbar osteoporotic vertebral fractures. J Orthop Trauma 2004; 18:294-299.

8. Garfin S, Yuan H, Reiley M. New technologies in spine: Kyphoplasty and vertebroplasty for the treatment of painful osteoporotic compression fractures. Spine 2001; 26:1511-1515.

9. Steinmann J, Tingey C, Cruz G, Dai Q. Biomechanical comparison of unipedicular versus bipedicular kyphoplasty. Spine 2005; 2:201-205.

10. Tohmeh A, Mathis J, Fenton D, Levine A, Belkoff S. Biomechanical efficacy of unipedicular versus bipedicular vertebroplasty for the management of osteoporotic compression fractures. Spine 1999; 17:1772-1776.

11. Jadad A, Cook D, Browman G. A guide to interpreting discordant systematic reviews. Canadian Medical Association Journal 1997; 10:1411-1416.

12. Panic N, Leoncini E, Belvis G, Ricciardi W, Boccia S. Evaluation of the endorsement of the Preferred Reporting Items for Systematic Reviews and Meta- Analysis (PRISMA) statement on the quality of published systematic review and metaanalyses. Plos One 2013; 12:e83138.

13. Shea B, Grimshaw J, Wells G, Boers M, Andersson N, Hamel C, Porter A, Tugwell P, Moher D, Bouter L. Development of AMSTAR: A measurement tool to assess the methodological quality of systematic reviews. BMC Med Res Methodol 2007; 7:10.

14. Wright J, Swiontkowski M, Heckman J. Introducing levels of evidence to the journal. J Bone Joint Surg Am 2003; 1:1-3.

15. Higgins J, Thompson S, Deeks J, Altman D. Measuring inconsistency in metaanalyses. BMJ 2003; 7414:557-56o.

16. Guyatt G, Oxman A, Vist G, Kunz R Falck-Ytter $Y$, Alonso-Coello $P$, Schünemann H. GRADE: An emerging consensus on rating quality of evidence and strength of recommendations. BM] 2008; 336:924-926.

17. Sun H, Lu P, Liu Y, Shen X, Sun E, Yang $H$. Can unilateral kyphoplasty replace bilateral kyphoplasty in treatment of osteoporotic vertebral compression fractures? A systematic review and meta-analysis. Pain Physician 2016; 19:551-563.

18. Feng $H$, Huang $P$, Zhang $X$, Zheng $G$, Wang Y. Unilateral versus bilateral percutaneous kyphoplasty for osteoporotic vertebral compression fractures: a systematic review and meta-analysis of RCTs. Journal of Orthopaedic Research 2015; 33:1713-1723.

19. Huang Z, Wan S, Ning L, Han S. Is unilateral kyphoplasty as effective and safe as bilateral kyphoplasties for osteoporotic vertebral compression fractures? A meta-analysis. Clinical Orthopaedics and Related Research 2014; 472:2833-2842.

20. Lin J, Zhang L, Yang H. Unilateral versus bilateral balloon kyphoplasty for osteoporotic vertebral compression fractures. Pain Physician 2013; 16:447-453.

21. Yang L, Wang X, Zhou L, Fu Q. A Systematic review and meta-analysis of randomized controlled trials of unilateral versus bilateral kyphoplasty for osteoporotic vertebral compression fractures. Pain Physician 2013; 16:277-290.

22. Li L, Sun T, Liu Z, Zhang J, Zhang Y, Cai $\mathrm{Y}$, et al. Comparison of unipedicular and bipedicular percutaneous kyphoplasty for treating osteoporotic vertebral compression fractures: A meta-analysis. Chinese Medical Journal 2013; 20:3956-3961.

23. Young D. Policymakers, experts review evidence-based medicine. Amrican Jour- nal of Health-system Pharmacy 2005; 62:342-343.

24. Zhao J, Meng X, Liu L, Zeng X, Kan S. Early functional rehabilitation versus traditional immobilization for surgical Achilles tendon repair after acute rupture: A systematic review of overlapping meta-analyses. Scientific Reports 2017; 7:39871.

25. Ding F, Jia Z, Zhao Z, Xie L, Gao X, Ma $D$, Liu M. Total disc replacement versus fusion for lumbar degenerative disc disease: A systematic review of overlapping meta-analyses. European Spine Journal 2017; 26:806-815.

26. Xing D, Wang B, Liu Q, Ke Y, Xu Y, Li Z, Lin J. Intra-articular hyaluronic acid in treating knee osteoarthritis: A PRISMAcompliant systematic review of overlapping meta-analysis. Scientific Reports 2016; 6:32790.

27. Zhang Q, Liu F, Xiao Z, Li Z, Wang B, Dong J, Han Y, Zhou D, Li J. Internal versus external fixation for the treatment of distal radial fractures. Medicine 2016; 95:e2945

28. Zhao J, Wang J, Long L. Surgical versus conservative treatments for displaced midshaft clavicular fractures. Medicine 2015; 94:e1057.

29. Zhao J, Wang J, Wang C, Kan S. Intramedullary nail versus plate fixation for humeral shaft fractures. Medicine 2015; 94:e599.

30. Rachner T, Khosla S, Hofbauer L. Osteoporosis: Now and the future. The Lancet 2011; 377:1276-1287.

31. Rostom S, Allali F, Bennani L, Abouqal R, Hajjaj-Hassouni N. The prevalence of vertebral fractures and health-related quality of life in postmenopausal women. Rheumatology International 2012; 4:971-980.

32. Kado D, Duong T, Stone K, Ensrud K, Nevitt M, Greendale G, Cummings S. Incident vertebral fractures and mortality in older women: A prospective study. Osteoporosis International 2003; 14:589-594

33. Jung $H$, Park $Y$, Seo H, Lee J, An K, Kim J, Shin B, Kang T, Park S. Quality of life in patients with osteoporotic vertebral compression fractures. J Bone Metab 2017; 3:187-196.

34. Theodorou D, Theodorou S, Duncan T, Garfin S, Wong W. Percutaneous balloon kyphoplasty for the correction of spinal deformity in painful vertebral 
body compression fractures. Clinical Imaging 2002; 1:1-5.

35. Goz V, Koehler S, Egorova N, Moskowitz A, Guillerme S, Hecht A, Qureshi S. Kyphoplasty and vertebroplasty: Trends in use in ambulatory and inpatient settings. The Spine Journal 2011; 11:737-744.

36. Kim D, Vaccaro A. Osteoporotic compression fractures of the spine; current options and considerations for treatment. The Spine Journal 2006; 6:479-487.

37. Han S, Wan S, Ning L, Tong Y, Zhang J, Fan S. Percutaneous vertebroplasty versus balloon kyphoplasty for treatment of osteoporotic vertebral compression fracture: A meta-analysis of randomised and non-randomised controlled trials. International Orthopaedics 2011; 35:1349-1358.

38. Andrei D, Popa I, Brad S, lancu A, Oprea M, Vasilian C, Poenaru D. The variabil- ity of vertebral body volume and pain associated with osteoporotic vertebral fractures: Conservative treatment versus percutaneous transpedicular vertebroplasty. International Orthopaedics 2017; 41:963-968.

39. Cheng $\mathrm{X}$, Long $\mathrm{H}, \mathrm{Xu}$ J, Huang $\mathrm{Y}$, Li F. Comparison of unilateral versus bilateral percutaneous kyphoplasty for the treatment of patients with osteoporosis vertebral compression fracture (OVCF): A systematic review and metaanalysis. European Spine Journal 2016; 25:3439-3449.

40. Chang W, Zhang X, Jiao N, Yuwen P, Zhu Y, Zhang F, Chen W. Unilateral versus bilateral percutaneous kyphoplasty for osteoporotic vertebral compression fractures: A meta-analysis. Medicine 2017; 96:e6738.

41. Lin D, Hao J, Li L, Wang L, Zhang H,
Zou W, Lian K. Effect of bone cement volume fraction on adjacent vertebral fractures after unilateral percutaneous kyphoplasty. Journal of Spinal Disorders and Techniques 2016; 3:E270-E275.

42. Fribourg D, Tang C, Sra P, Delamarter $\mathrm{R}$, Bae $\mathrm{H}$. Incidence of subsequent vertebral fracture after kyphoplasty. Spine 2004; 29:2270-2276.

43. Belkoff S, Mathis J, Jasper L, Deramond $\mathrm{H}$. The biomechanics of vertebroplasty. The effect of cement volume on mechanical behavior. Spine 2001; 14:1537-1541.

44. Kolb J, Kueny R, Püschel K, Boger A, Rueger J, Morlock M, Huber G, Lehmann W. Does the cement stiffness affect fatigue fracture strength of vertebrae after cement augmentation in osteoporotic patients? European Spine Journal 2013; 7:1650-1656. 